\title{
Contingency Plans Revealed by CNES
}

from La Recherche.

THE French unveiled plans this week designed to save the crumbling ELDO partnership. The reluctance of Germany to participate in the Europa III project has caused France to come out with details of a cheaper and, it claims, a more reliable launcher.

This move has been precipitated by the German preference to take part in building the exit module for the space shuttle which, in French eyes, implies that they are moving farther away from the concept of a European launcher.

France is well known to be reluctant to base a European space programme on launchers obtained from the United States and recently both $\mathrm{Mr}$ Michel Debré and $\mathrm{Mr}$ Charbonnel, Minister for Industrial and Scientific Development, have come out strongly in favour of a French national launching pro. gramme.

Details of the French plan, presented this week to the conference of European Ministers for Research, were first revealed at an international congress organized by the Centre National d'Etudes Spatiales (CNES) at Kourou in French Guiana at the end of November.

The proposed replacement is a three stage rocket in contrast with the two stage Europa III. France claims that this launcher can provide the same performance as Europa III but at a cost of Fr 2,200 million, compared with the estimated $\mathrm{Fr} 3,000$ million which it would cost to develop Europa III.

The French government proposes that it should meet 75 per cent of the cost of the new launcher-Fr 1,700 million, which is $\mathrm{Fr} 300$ million more than it would have contributed to Europa. III. The extra cost would be carried by the French Ministry for the Army which sees an autonomous European launcher as a basis for launching observation and navigation satellites.

The first stage of the three stage launcher will be the same as that which is planned to form the first stage of Europa III-four Viking 2 engines developed by the Société European de Propulsion. The second stage is to have one Viking 2 engine but the last stage will have a single cryogenic engine also developed in France. French project managers claim that this combination will be much more reliable than the Europa III launcher-particularly as the proposed second stage of Europa III consists of a complex cryogenic high pressure engine which, say the French, is far from reliable. This, according to the French, should assure the German politicians, who are particularly concerned with the disastrous failures of Europa launchers, that their proposed launcher is based on well proven technologies.

Naturally enough France wants to have overall responsibility for the launcher-only 25 per cent of the cost is to be shared among her partners in ELDO-but it is hoped that European industry will contribute to its construction.

A question which is certain to be asked before decisions are taken on

\section{WOLFSON FOUNDATION \\ Train Research}

THE Wolfson Foundation is to make grants worth about $£ 1.25$ million to support sixteen more university projects orientated to the needs of industry. This brings the total amount of money spent by the foundation in this way to about $£ 3$ million, and since the scheme started in 1968 forty projects have been funded (see Nature, 231, 75; 1971).

Prominent among the most recent awards are two concerned with research into magnetically levitated trains. The institutions concerned are the University of Warwick, where $£ 147,750$ is to be made available over the next five years to the Department of Engineering, and the School of Applied Sciences of the University of Sussex, which is to receive $£ 127,655$ over three years. The work at both these universities is naturally complemented by that in progress at the University of Wales Institute of Science and Technology (UWIST) where a centre for the technology of soft magnetic materials and their applications was set up two years ago with $£ 132,000$ from the Wolfson Foundation.

At Warwick it is planned to build a test vehicle that will be levitated above an aluminium track by means of superconducting magnets and propelled by a linear motor, whereas at Sussex conventional electromagnets and an iron rail on the track are to be used in a system involving magnetic attraction and a feedback control loop. And at UWIST a system based on the repulsive force between permanent magnets on the vehicle and on the track is being developed.

One of the advantages of using superconducting magnets is that they are lighter than their conventional the French plan is what use Europe will make of a launcher in the next twenty years. Last July, Germany, Britain and France made a survey of their scientific needs during 1980-90, and the remarkably consistent conclusions of each country are that between 40 and 50 launches will be needed in this decade.

France has argued that if European space plans were based entirely on launchers from the United States then only half this number of launches might be possible. Germany, on the other hand, feels that more than thirty of the launches would go ahead with United States launchers.

counterparts and allow clearances between vehicle and track of $25 \mathrm{~cm}$ or so, compared with the $1 \mathrm{~cm}$ or so that is possible with conventional magnetic methods. Even the air cushioned vehicle being developed by Tracked Hovercraft Limited, the protégé of the National Research Development Corporation, can hover only a few centimetres above its track.

Professor J. A. Shercliff, head of the School of Engineering Science at the University of Warwick, said last week that the work there will be directed towards a train capable of travelling at 300 to 500 miles an hour. He also said that the relatively large clearance possible between vehicle and track means that the tolerance in construction of the track will probably not need to be much greater than that of a normal road. Dr R. G. Rhodes, who is directly concerned with the Warwick project, points out that the Japanese have in the past few weeks announced the successful levitation of a vehicle weighing 4.5 tons using superconducting magnets. Much more government support for research into magnetically levitated trains is urgently needed, according to Dr Rhodes, otherwise the systems being developed by German companies (for example, Siemens) with government support, may win the day unchallenged.

Among the other projects which are to be financed by the Wolfson Foundation from the beginning of next year are the establishment of a unit at the University of Edinburgh for high speed liquid chromatography $(£ 92,500)$, the setting up of an Institute of Offshore Engineering at Heriot-Watt University $(£ 177,790)$ and the financing, for a period of five years, of a Chair of Energetics at the University of Newcastle upon Tyne $(£ 37,500)$. 